\title{
Analysis of the crack-crack interaction effect initiated in aeronautical structures and repaired by composite patch
}

\author{
Nour Chafak Mohamed Ibrahim, Serier Boualem, Mechab Belaïd \\ University of Djillali Liabes, LPMM Laboratory, Sidi Bel Abbes, Algeria \\ nor_achafak@yahoo.fr,serielem@yahoo.com,bmechab@yahoo.fr
}

\begin{abstract}
In this work, we analyze three - dimensionally, by the finite element method, the performance of the repair of aeronautical structures damaged by cracking and repaired by patch of composite materials. The effect of crack-crack interaction according to their position and interdistance was analyzed. The criterion of rupture retained for this study is the factor of intensity of constraints. We show that this factor increases considerably and reaches a critical threshold when the two cracks develop towards each other. The repair of such damage using a composite patch ensures the stability of this structure during the commissioning process. The sharp fall in the stress intensity factor is characteristic of this stability.
\end{abstract}

KeYwORDs. Plate; Repair; Adhesive; Patch; Composite materials; Crack; Finite elements; Stress intensity factor.

\section{OPEN ACCESS}

Citation: Ibrahim, N. C. M., Serier, B., Mechab, B., Analysis of the crack-crack interaction effect initiated in aeronautical structures and repaired by composite patch, Frattura ed Integrità Strutturale, 46 (2018) 140-149.

Received: 05.06 .2018

Accepted: 12.07 .2018

Published: 01.10 .2018

Copyright: (C) 2018 This is an open access article under the terms of the CC-BY 4.0, which permits unrestricted use, distribution, and reproduction in any medium, provided the original author and source are credited.

\section{INTRODUCTION}

$\mathrm{T}$ echniques for repairing and reinforcing damaged structures by bonding composite patches are increasingly used in industry, with the aim of delaying the appearance or propagation of fatigue cracks. In this technique, a composite patch is assembled to the damaged part with an adhesive, the aim of which is to transmit the maximum of stresses of the plate to the patch through the adhesive in order to reduce them to the Tip of the crack. The notches are the main cause of the initiation of the crack and thus the repair with composite patches can play an important role, on the other hand, in reducing the stress concentration at the tip of the crack, And on the other hand of the reduction of the intensity of the stresses at the crack tip. Therefore, the bonding assembly has several advantages, the possibility of assembling different materials, weight reduction, high stiffness, good fatigue strength, shock reduction and ease of bring together the most complex shapes. This technique has been extensively studied, where the stress intensity factor is considered an important factor in estimating the residual lifetime of cracked structures. In order to improve this technique, several experimental, numerical and even analytical studies have been devoted to the study of this behavior. The work was launched, in 1984, by Baker at the Australian Research Laboratory ARL. [1, 2]. Analytically, several works have been devoted to understanding this class of problems represent the effect of the patch on the crack tip stress intensity factor such as, Mitchell and al. [3], Jones and Callinan [4], Rose [5 - 7], Young and al. [8, 9], Rooke and al [10], Ramesh Chandra and al., [11] Liu and Fan [12], Arendt and Sun [13]. Numerically, several authors have shown that the stress intensity factor depends on several parameters, the size and position of the crack, the patch and adhesive dimensions, the 
mechanical properties of the patch, the adhesive and of the structure itself, and have shown that, after repair, the stress intensity factor exhibits asymptotic behavior when the length of the crack increases as Fekirini and al.[14], Belhouari and al.[15] et Bachir Bouiadjra [16] Which also showed that an adhesive with a high shear modulus gives a low stress intensity factor at the end of the repaired cracks. Therefore, they recommend the use of these types of adhesives to increase the performance of the repair. However, the higher the adhesive shear modulus leads to higher adhesive stresses, which increases the risk of adhesive failure. They also analyzed the thickness importance of the adhesive and concluded that the adhesive properties should be optimized to improve repair performance and avoid adhesive breaking. Ouinas and al. [17] made a comparison between the boron / epoxy patch and the graphite / epoxy patch for repairing aircraft structures. They indicated that the reduction of the stress intensity factor at the crack tip is more important for the boron / epoxy patch. Ouinas and al. [18,19], Mhamdia and al. [20] they analyzed the effect of the shape of the composite patch on the repair of aircraft structures. These authors analysed the performance of the repair is related to the patch shape, where they showed that the effectiveness of the rectangular shape of the plate can be greatly improved if this shape is modified in "H" or arrow shapes. The latter shape reduces: the stress intensity factor at the tip of the crack, the mass of the composite patch and therefore the repair cost, the adhesive stresses what improves the durability of the repair.

The repair of doubly cracked structures is the objective of this study, where the interconnection of these cracks leads to the ruin of the structure. Thus, the presence of a crack in the vicinity close to another leads to an increase in the probability of instability of these cracks by an intensification of the FIC. The subcritical size of this narrow crack is about 3 times when the cracks are close to each other. Such a fissure arrangement can be fatal to the structures, thus leading to their break. In order to delay this interconnection during commissioning and consequently to improve the service life. The latter is analyzed in terms of stress intensity factor, which depends on the stress applied, the size of the cracks, and their interdistance.

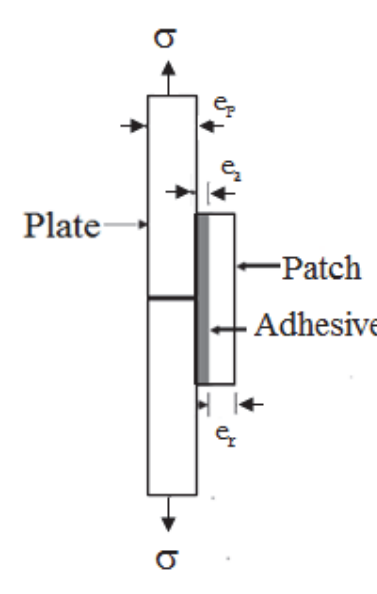

(a)

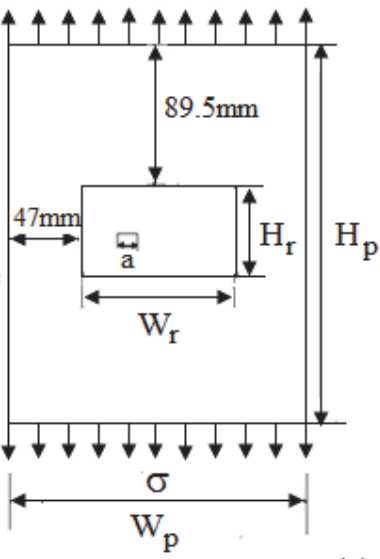

(b)

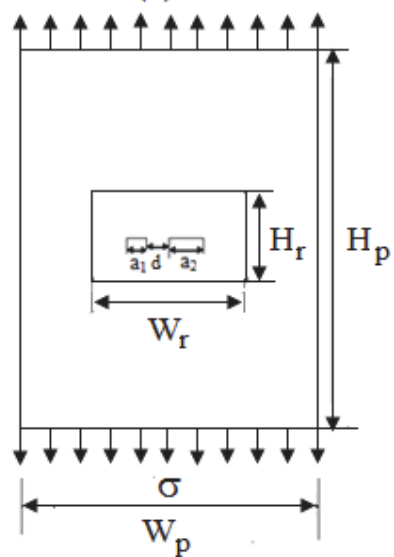

(c)

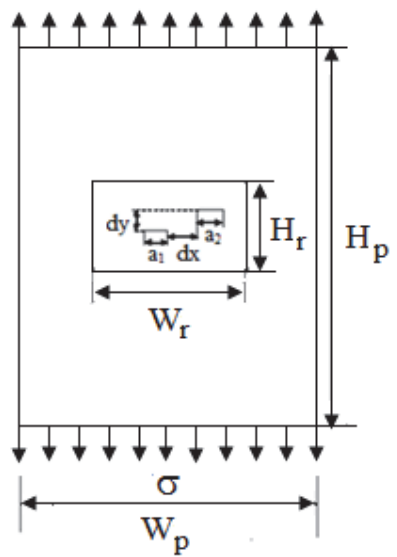

Figure: 1 Geometrical models containing, (a) central crack of size "a", (b) Two parallel cracks, (c) two parallel central fissures distant from $(\mathrm{dx})$ and (dy). 


\section{GEOMETRICAL AND FE MODELS}

$\mathrm{T}$

he geometric model of the 2024 T3 aluminum alloy plate cracked repaired by boron-epoxy composite patch is shown in Fig. 1. The plate is characterized by its height $\mathrm{H}_{\mathrm{p}}=254 \mathrm{~mm}$, its width $\mathrm{W}_{\mathrm{p}}=254 \mathrm{~mm}$ and its thickness $\mathrm{e}_{\mathrm{p}}$ $=3 \mathrm{~mm}$. The patch of dimensions $\mathrm{H}_{\mathrm{r}}=75 \mathrm{~mm}, \mathrm{~W}_{\mathrm{r}}=160 \mathrm{~mm}, \mathrm{e}_{\mathrm{r}}=3 \mathrm{~mm}$ is bonded to the plate by an adhesive type FM73 of thickness $e_{a}=0.26 \mathrm{~mm}$.

The unrepaired and repaired cracked plate is subjected to uniaxial tension efforts of varying amplitude. The mechanical properties of the plate, the patch and the adhesive are shown in Tab. 1.

The complete structure was modeled by cubic elements (hexahedrons) at eight nodes for the analysis of the stress intensity factor (Fig. 2a, Fig. 2b, Fig. 2c). The rectangular shape of the composite patch is identifiable in this figure, a regular mesh is made for the whole structure, this mesh remains the same throughout the calculation.

The crack results in a geometric singularity causing a concentration of stress. Therefore, a refined mesh is made around the crack. The total number of elements of the structure containing:

- A central crack of size "a" (Fig. 1a) is equal to 22716.

- Two central and parallel cracks, distant from " dx" (Fig. 1b) is equal to 26160.

- Two central and parallel cracks distant from dx " and " dy " (Fig. 1c) is equal to 51960.

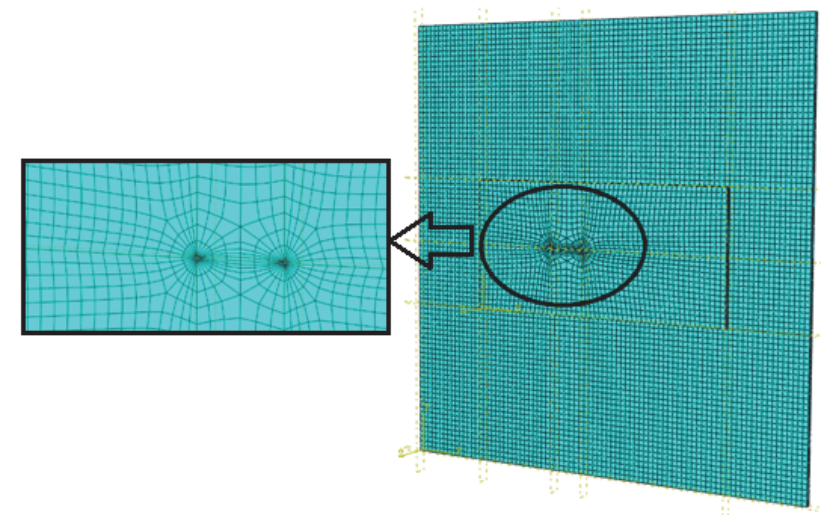

(a)

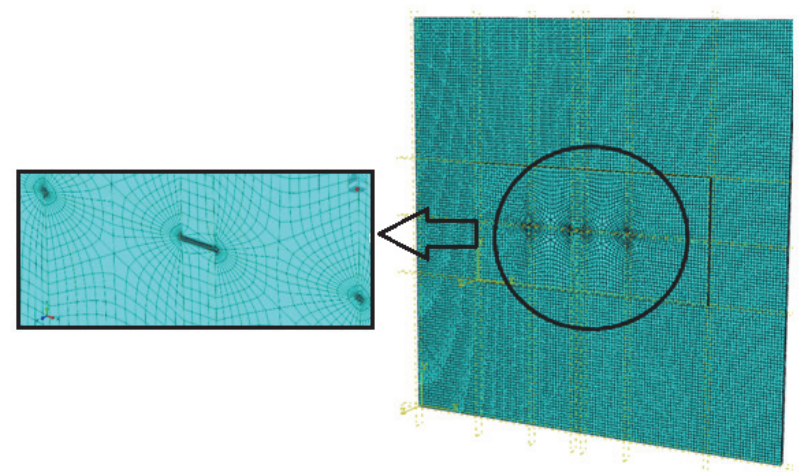

(b)
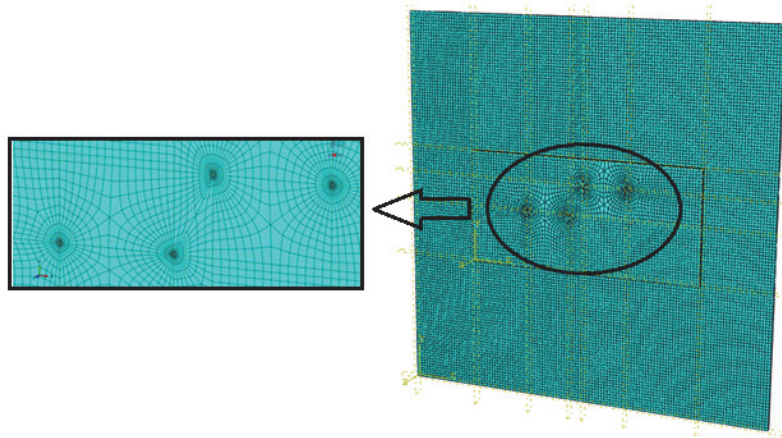

(c)

Figure 2: Meshing models containing, (a) central crack of size "a", (b) Two parallel cracks, (c) two Parallel central fissures distant from $(\mathrm{dx})$ and $(\mathrm{dy})$.

\section{RESULTS AND DISCUSSION}

\section{A central crack of size " $a$ " - Effect of loading}

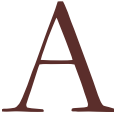
three-dimensional numerical analysis by the finite element method of the breaking mechanical behavior of an aluminum plate Al $2024 \mathrm{~T} 3$ containing a central crack of size "a" initiated perpendicular to the direction of stresses and subjected to uniaxial tensile load. The criterion of rupture selected for this study is the factor of stress intensity in mode of opening (mode I). The results thus obtained are represented in Fig. 3a. The latter shows that 
an increase in this crack results in an intensification of this factor. This behavior is accentuated by an increase in mechanical efforts.

\begin{tabular}{|c|c|c|c|c|}
\hline Property & $\begin{array}{l}\text { Aluminum } \\
\text { (Al T2024) }\end{array}$ & $\begin{array}{r}\text { Material } \\
\text { Boron/Epoxy }\end{array}$ & $\begin{array}{l}\text { Adhesive } \\
\text { FM } 73\end{array}$ & Description \\
\hline $\mathrm{E}_{1}$ & 72 & 200 & 2.55 & Young's modulus in $\mathrm{X}$ direction (GPa) \\
\hline $\mathrm{E}_{2}$ & & 25 & & Young's modulus in Y direction (GPa) \\
\hline $\mathrm{E}_{3}$ & & 25 & & Young's modulus in $\mathrm{Z}$ direction (GPa) \\
\hline$v_{12}$ & 0.33 & 0.21 & 0.32 & Poisson's Ratio in X-Y plan \\
\hline$v_{13}$ & & 0.21 & & Poisson's Ratio in X-Z plan \\
\hline$v_{23}$ & & 0.21 & & Poisson's Ratio in Y-Z plan \\
\hline $\mathrm{G}_{12}$ & & 7.2 & & Shear modulus in $\mathrm{X}-\mathrm{Y}$ plan $(\mathrm{GPa})$ \\
\hline $\mathrm{G}_{13}$ & & 5.5 & & Shear modulus in $\mathrm{X}-\mathrm{Z}$ plan $(\mathrm{GPa})$ \\
\hline $\mathrm{G}_{23}$ & & 5.5 & & Shear modulus in $\mathrm{Y}-\mathrm{Z}$ plan $(\mathrm{GPa})$ \\
\hline
\end{tabular}

Table 1: Mechanical proprieties of materials.

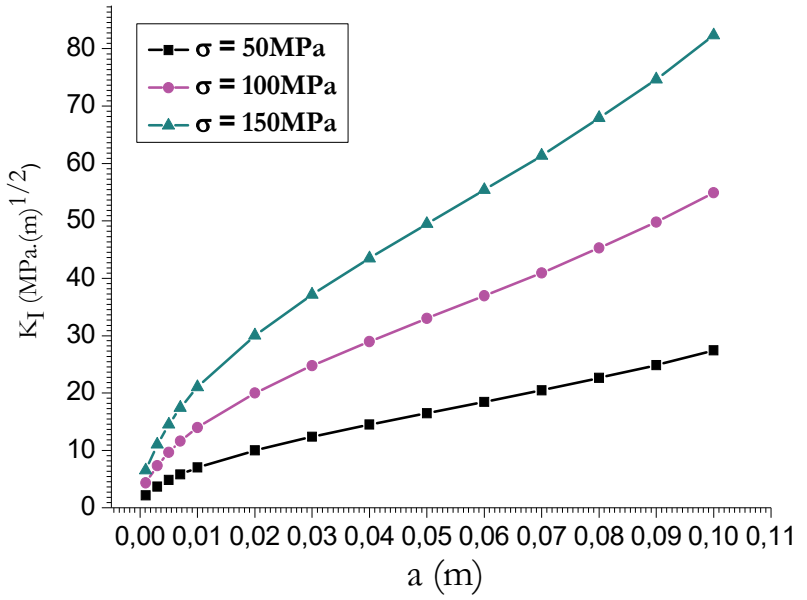

(a)

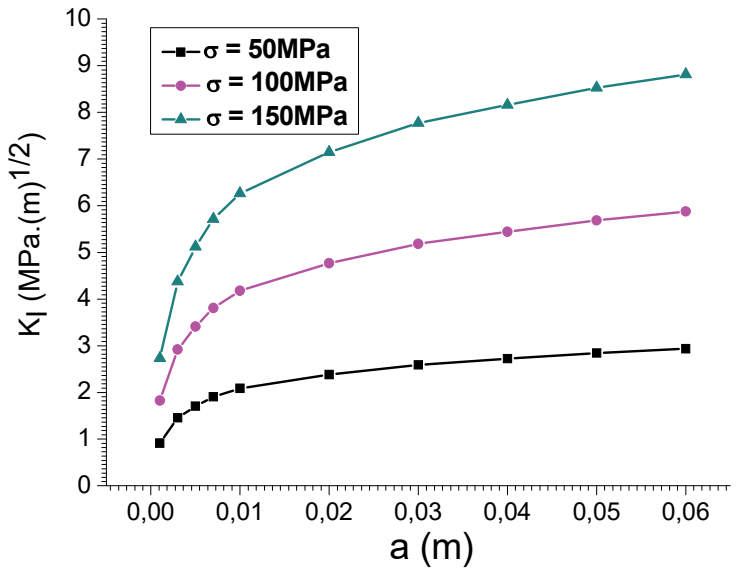

(b)

Figure 3: Variation of stress intensity factor in crack heads as a function of crack size and mechanical loading intensity: (a) unrepaired, (b) repaired.

The area of the plate initially damaged by cracking is repaired by patch of composite material and then tested in uniaxial tension. In Fig. $3 \mathrm{~b}$ are shown the results obtained from this analysis. This figure clearly shows that the repair begets a large reduction (about ten times) in the stress intensity factor. The variation of this rupture criterion with the size of the crack is an asymptotic variation. Such behavior shows that the crack propagation kinetics are greatly reduced, thus resulting in crack stability. The durability of such a structure is therefore considerably increased, and this for large size defects subjected to heavy loading.

\section{Crack-crack interaction - Two central and parallel cracks}

In this part of the work, we analyze the rupture behavior of an Al 2024T3 plate containing two cracks aligned on the same axis perpendicular to that of the mechanical stresses. This structure is tested in uniaxial tension (Fig. 1b). The Fig. 4a illustrates the variation in the stress intensity factor in the opening mode in heads of the first unrepaired crack (Fig. 1b) as a function of the distance separating it from the second. This figure shows that a growth of the latter towards the first 
greatly increases the mechanical energy in crack heads. The stress intensity factor doubles practically in intensity when the two cracks are located in the vicinity close to each other. There is thus an interdistance between these two defects beyond which this criterion of rupture increases very strongly. This increase is all the more important as the plate more strongly Mechanically solicited. The increase of this rupture criterion is explained by the simultaneous interaction of the stress fields in the heads of these two cracks. The increase of this rupture criterion is explained by the simultaneous interaction of the stress fields in the heads of these two cracks. This shows that a development from one fissure to another causes their instability and favors their coalescence. The interaction effect tends to disappear when these two defects are located far from one another.

This structure, containing two cracks, is repaired using a patch made of composite material (Fig. 2b) of the same size as that used for the repair of a crack and then subjected to traction. The variation of the stress intensity factor in mode I in the tip of the first repaired crack as a function of the distance with respect to the second crack is illustrated in Fig. 4b. The repair leads to a considerable fall of this criterion of rupture. A large part of the mechanical energy concentrated in crack tips is absorbed by the patch through the adhesive. This leads to the stability of these two cracks and therefore to their non-coalescence, thus leading to an increase in the duration of such a structure.

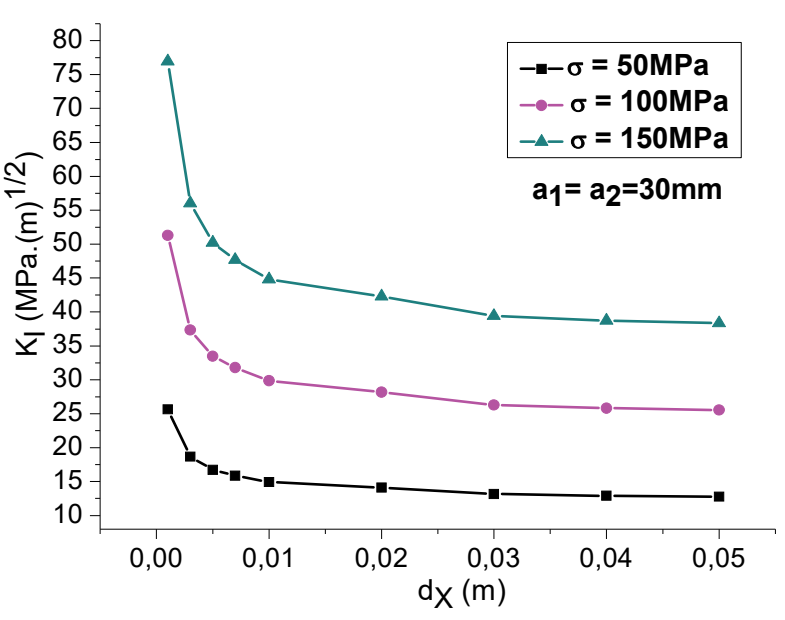

(a)

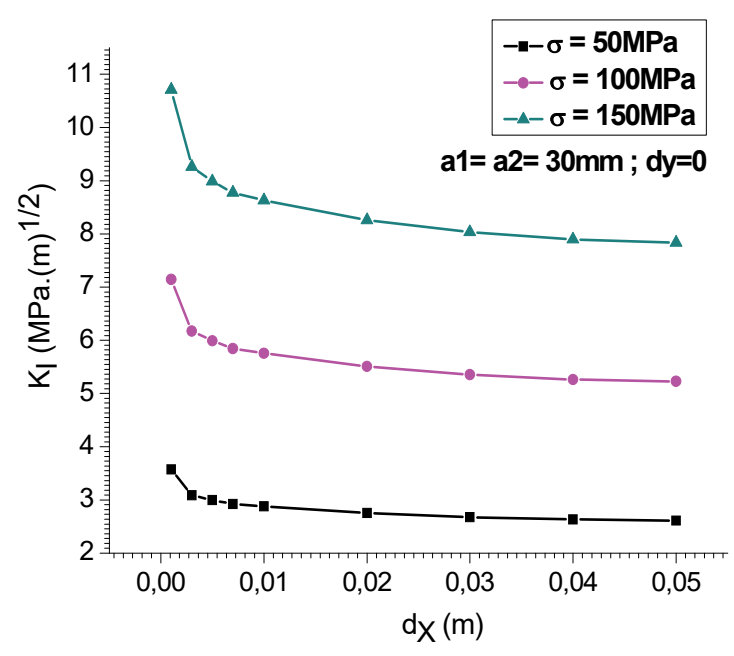

(b)

Figure 4: Variation of the stress intensity factor in heads of the first crack as a function of the distance with respect to the second crack: (a) unrepaired, (b) repaired.

For an illustration of the effect of the repair we have shown in the Fig. 5 is the variation of the stress intensity factor in the opening mode in heads of the first crack as a function of the distance separating it from the second initiated crack In a non-repaired and repaired plate. This figure shows that the adhesion of a composite patch to the damaged part by cracking of the plate, as a repair technique, leads to a very great reduction in this rupture criterion, approximately eight times smaller than that resulting from cracks not repaired. Beyond a certain distance between these two cracks the stress intensity factor varies very little with the reduction with this distance.

The effect of the size of the first crack on the localized stress intensity factor at a distance "dx" from the second crack is illustrated in Fig. 6a. We note that a development of this defect leads to an increase in mechanical energy in crack tips and that this energy is all the more significant as this crack approaches the second. The stress intensity factor is closely related not only to the size of the crack, is propagating but also to the distance separating it from the second crack. The interaction of the stress fields in points of the two cracks leads to an increase in the stress intensity factor. The variation of this factor resulting from such a plate containing two repaired cracks, as a function of the size of the first crack and its distance from the second defect, is shown in Fig. 6b. The latter shows that repair has considerably reduced this factor. A very high proportion of stresses in crack tips is transferred from the damaged plate to the composite patch through the adhesive, thus causing the stability of these two defects and consequently the increase in the duration of these structures. The effect of the size of the second crack on the stress intensity factor in the heads of the first crack initiated in an unrepaired plate is shown in Fig. 7a. The latter shows that a development of the second crack towards the first favors its instability characterized by an increase of this criterion of rupture. Indeed, the field of stresses in points of the first crack is all the more important as the second crack propagates in the direction of the first. The level of these constraints increases 
considerably when the second tends towards the first. This behavior favors their coalescence. The Fig. $7 \mathrm{~b}$ shows the variation in the stress intensity factor resulting from the same structure but repaired. The analysis of this figure shows the beneficial effect of the repair. The stress intensity factor in points of the first crack fell sharply, regardless of the size of the second crack. Under the effect of the repair, the zone of strong of stresses interaction was strongly relaxed. This clearly shows that the repair technique considerably reduces the risk of coalescence of cracks resulting from the mechanism of interaction between stress fields in crack heads.

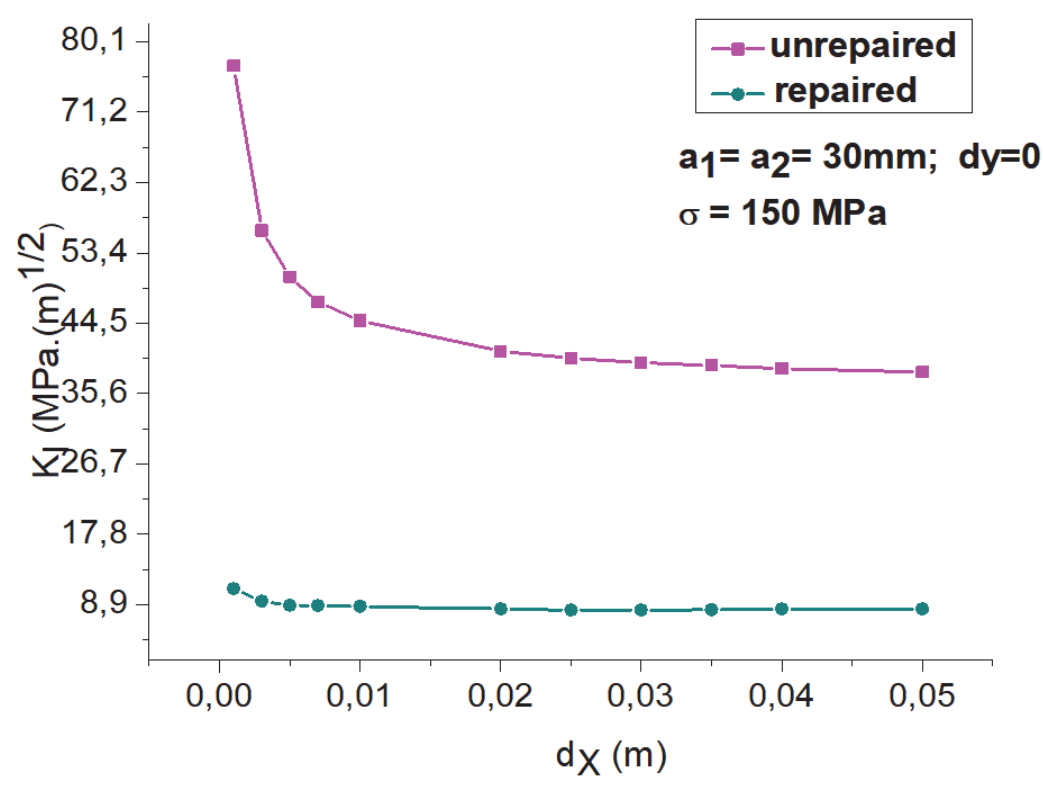

Figure 5: Variation of the stress intensity factor in the heads of the first crack as a function of the distance separating it from the second initiated in an unrepaired and repaired plate.

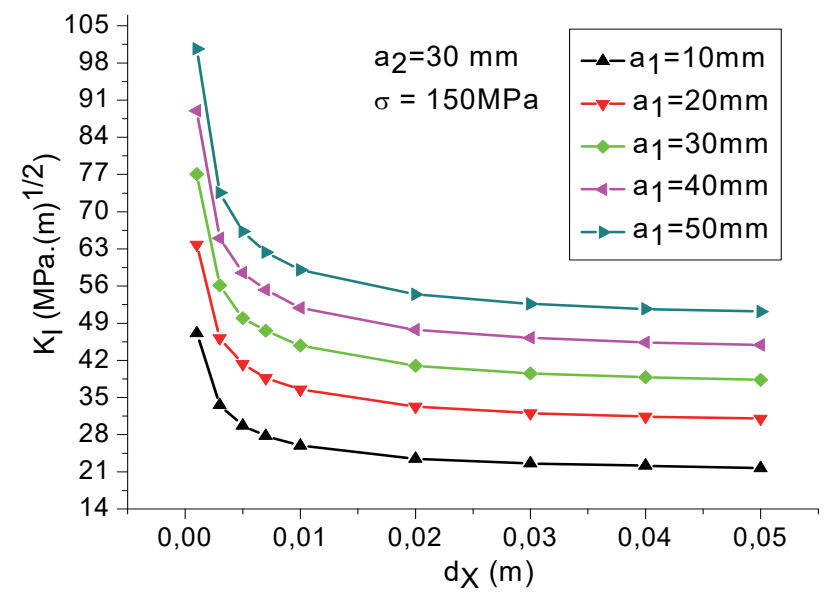

(a)

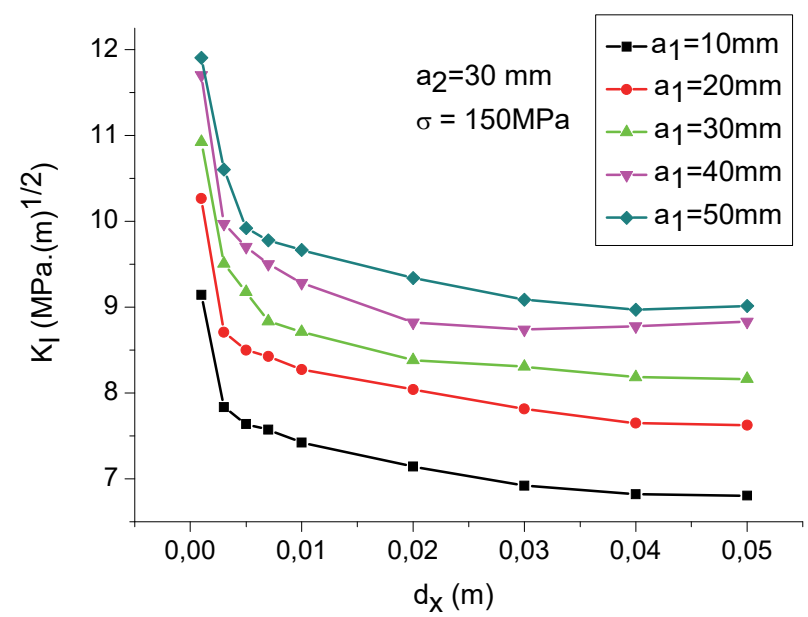

(b)

Figure 6: Variation of the stress intensity factor in heads of the first crack as a function of its size: (a) unrepaired, (b) repaired.

The effect of the simultaneous propagation of the two unrepaired cracks on the stress intensity factor in spikes of the first crack is illustrated in Fig. 8a. We note, however, that the risk of instability of the first crack is all the higher as the second propagates in its direction and these two defects develop simultaneously towards each other. The stress intensity factor resulting from the first crack increases with the growth of these two cracks. Such behavior promotes their coalescence by interaction effect. A patch repair of such a structure leads to a strong of stresses relaxation in crack tips characterized by a low stress intensity factor irrespective of the size of these two defects (Fig. 8b). 


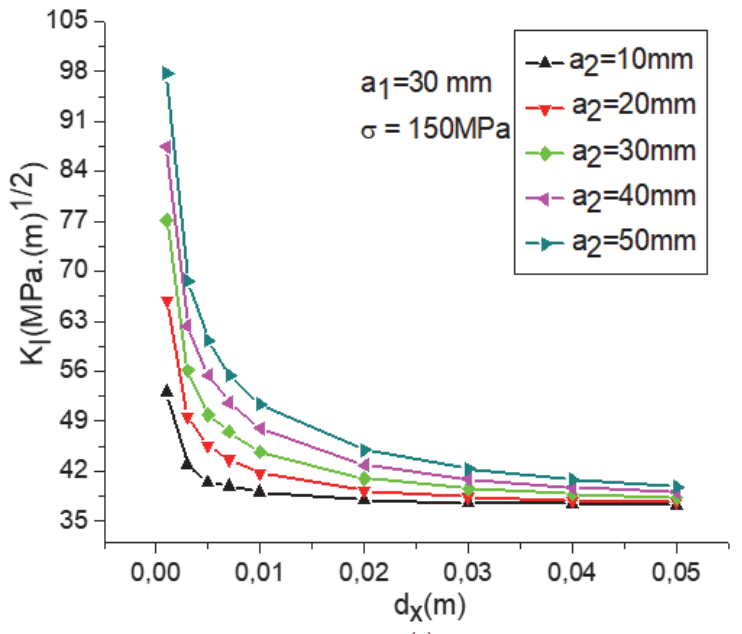

(a)

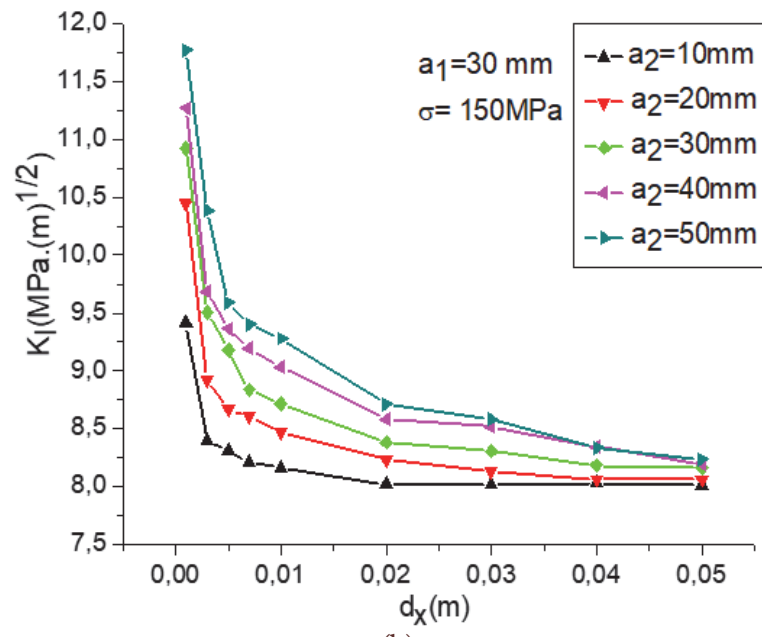

(b)

Figure 7: Variation of the stress intensity factor in heads of the first crack as a function of the size of the second crack: (a) not repaired, (b) repaired.

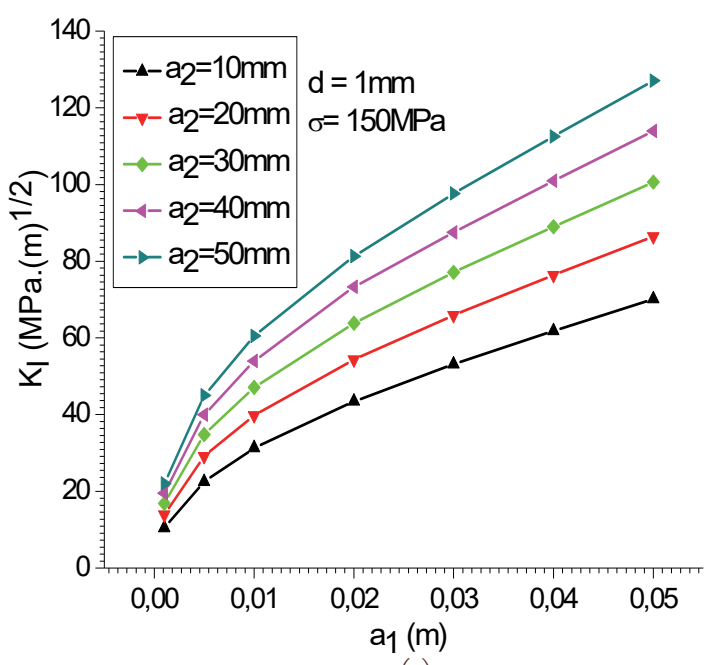

(a)

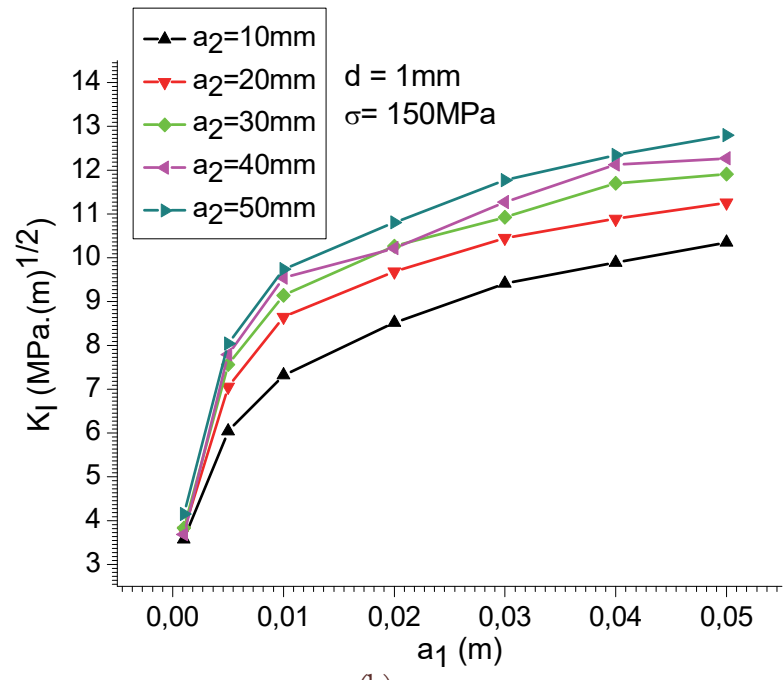

(b)

Figure 8: Variation of the stress intensity factor in heads of the first crack as a function of the size of two cracks: (a) unrepaired, (b) repaired

Two central and parallel cracks distant from $d x$ " and " $d y$ "

The Fig. 9 shows that the mode I stress intensity factor at the point of the mobile crack decreases as it tends to approach the immovable defect. The interaction effect disappears when these defects tend to coalesce. Such an arrangement of these two cracks are dangerous as when they are parallel and opposite. In this case these two defects behave one Only one. The repair by composite patch of this plate containing such cracks results in a marked improvement in its durability by a strong reduction of this breaking criterion as shown in Fig. 9.

In this part of the work, the stress intensity factor in heads of the first crack is analyzed as a function of the two distances (horizontal and vertical denoted $\mathrm{dx}$ and dy respectively) separating it to a second crack. The results thus obtained are illustrated in FIG. 10a. We note that a strong reduction of these two geometric parameters leads to a sudden increase of this criterion of rupture. Such a localization favors their instability by intensifying the mechanical energy in crack tips. This strong interaction of the energies leads to the coalescence of these two defects and therefore to the sudden rupture of the plate. The repair of such a structure results in a clear decrease in the stress intensity factor (Fig. 10b).

The shear stresses in the adhesive are relatively low as shown in Fig. 11. This figure clearly illustrates that the transfer of stress resulting from the interaction effect between two cracks, from the plate to the patch, is done Easy way. The transfer 
is explained by low values of the greatest tangential stresses in the adhesive layer. Even the strongest interactions between the two cracks, defined here by $\mathrm{d}=1 \mathrm{~mm}$ (Fig. 1), induce relatively high shear stresses in the glue. It is clear that the refraction of such cracks (interaction of two cracks), initially highly unstable, (FIC in mode I) high disadvantaged their coalescence and ensures their stability. The stresses generated for such a location in the adhesive are relatively and do not present any risk of damage to the adhesive by cohesive or adhesive rupture.

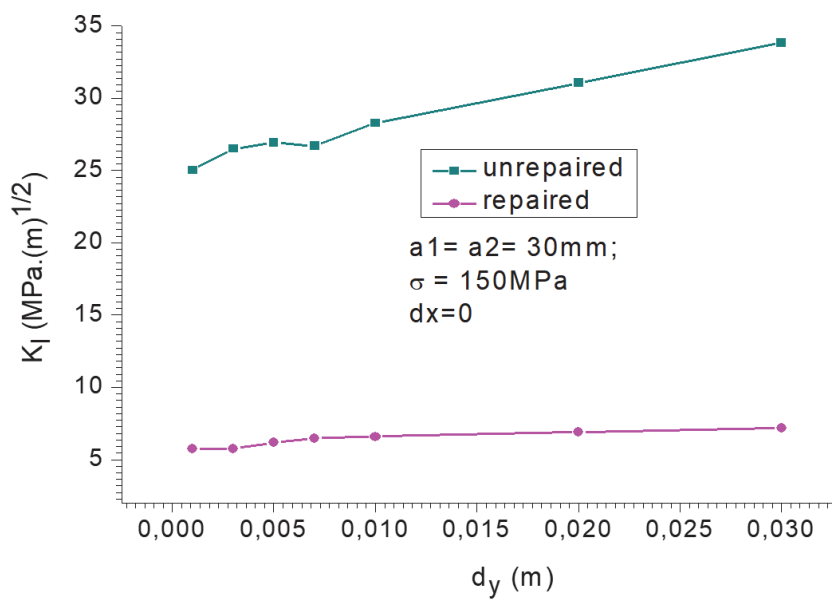

Figure 9: Variation of the stress intensity factor in heads of the first crack as a function of the size of two repaired and unrepaired cracks.

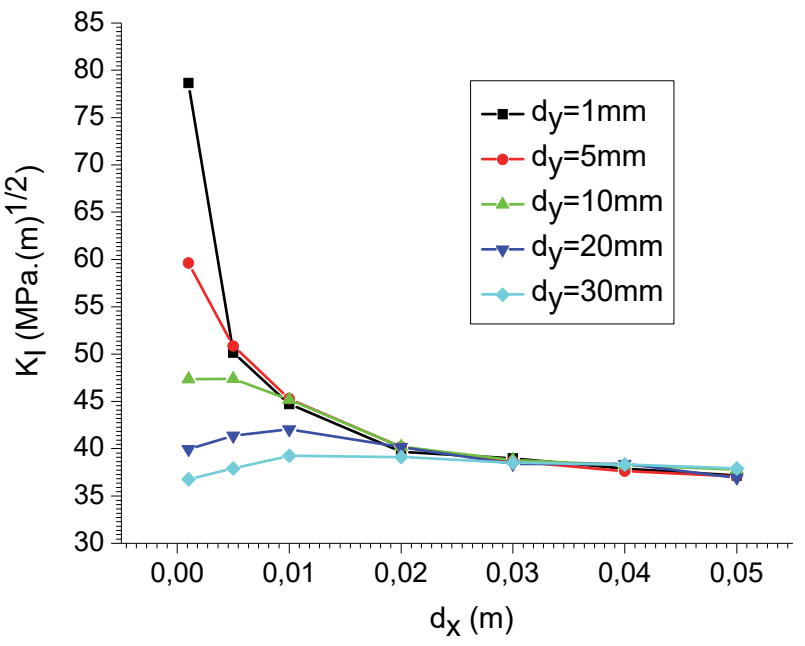

(a)

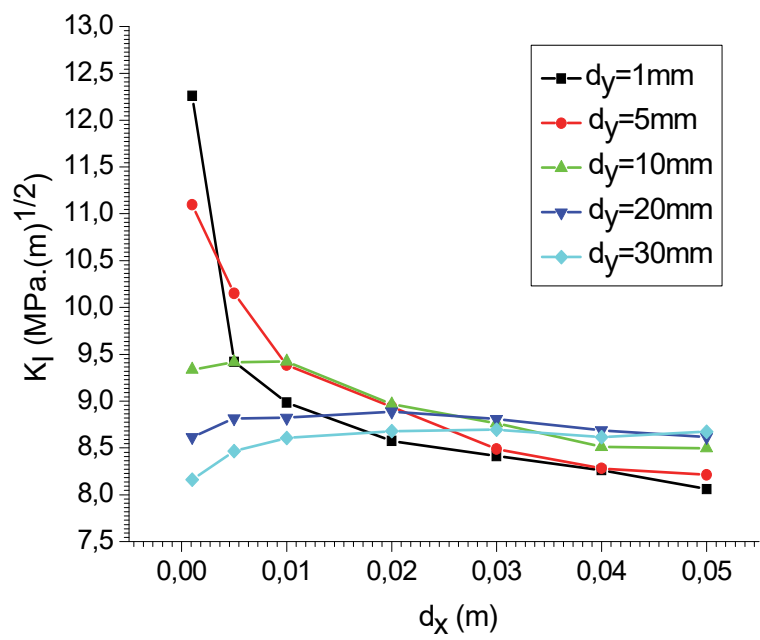

(b)

Figure 10: Variation of the stress intensity factor in the heads of the first crack as a function of the distances "dx" and "dy" separating it from the second crack of a structure: (a) unrepaired, (b) repaired

The stress relaxation in the near vicinity of interacting cracking fronts (low Mode I FIC) and tangential stresses in the adhesive layer promotes performance, reliability and durability of the repair.

\section{CONCLUSION}

$\mathrm{T}$

he results obtained in this work lead to the conclusion that:

-The stress intensity factor depends not only on the stress applied, on the size of the cracks, initiated along the transverse axis of the plate but also on their interdistance. It is the horizontal distances "dx" and vertical "dy" that 
separate these cracks which determine the value of the stress intensity factor. Simultaneous reduction of these two geometric parameters leads to a strong increase in the stress intensity factor reaching the critical breaking threshold

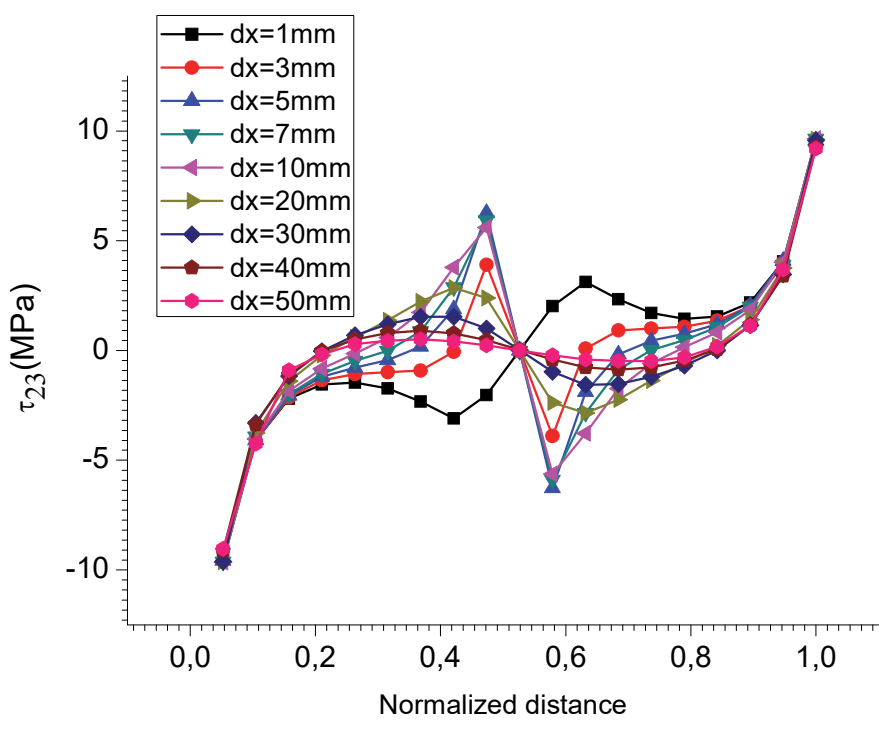

Figure 11: Variation of shear stresses in the adhesive.

-The repair with composite patch of such a structure leads to a very great reduction in the stress intensity factor. The cracks initially highly unstable, characterized by a steep slope at the curve $\mathrm{K}_{\mathrm{I}}=\mathrm{f}(\mathrm{d})$, see their kinetics of propagation greatly delayed. These defects do not have enough energy to propagate.

-The stress intensity factor resulting from a crack, distant from "dx" of another crack, increases with the mutual increase of these cracks. It reaches its maximum value when, during their growth, these two defects propagate towards each other. To the repair of such cracks results in a highly reduced stress intensity factor. This leads to a slowing down of the coalescence phenomenon of these two cracks;

-The stress relaxation in the near vicinity of interacting cracking fronts (low Mode I FIC) and tangential stresses in the adhesive layer promotes performance, reliability and durability of the repair.

\section{REFERENCES}

[1] Baker, A.A. (1984). Repair of cracked or defective metallic aircraft components with advanced fibre composites an overview of Australian work. Compos Struct. pp. 2153 -2581. DOI: 10.1016/0263-8223(84)90025-4.

[2] Baker, A.A. and Chester, R.J. (1993). Recent advances in bonded composite repair technology for metallic aircraft components. In: Chandra T, Dhingra AK, editors. Proceedings of the international conference on advanced composite materials, pp. 45-49.

[3] Mitchell, R.A., Woolley, R.M. and Chwirut, D.J. (1975). Analysis of Composite Reinforced Cut-outs and Cracks, AIAAJ.,13, pp. 744-749. DOI: 10.2514/3.60431.

[4] Jones, R. and Callinan, R.J. (1979). Finite Element Analysis of Patched Cracks, J. Struct.Mech. 7, pp. 107-130. DOI: $10.1080 / 03601217908905315$.

[5] Rose, L. R. F. (1981). An Application of Inclusion Analogy for Bonded Reinforcement. Int. J. of Solids Struct., 17827-838. DOI: 10.1016/0020-7683(81)90091-3.

[6] Rose, L. R. F. (1982). A Cracked Plate Repaired by Bonded Reinforcements, Int. J. Frac., 18, pp. 135-144. DOI:10.1007/BF00019638.

[7] Rose, L. R. F. (1987). Crack Reinforcement by Distributed spring. J. Mech. Phys. Solid.,3, pp. 5383-5340. DOI: 10.1016/0022-5096(87)90044-5.

[8] Young. A, Cartwright, D.J. and Rooke, D. P. (1985). Model Studies of Repair Patches. Proc of Int. Conf. On fatigue, Corrosion, Cracking, Fracture Mechanics and Failure Analysis, Salt Lake City, 339-346. 
[9] Young. A, Rooke, D. P. and Cartwright, D.J. (1989). Numerical Study of Balanced Patch Repairs to Cracked Sheet. Aero. J., pp. 327- 334. DOI: 10.1017/S0001924000017255.

[10] Rooke, D. P., Young, A. and Courtney, T.J. (1992). Effect of Repair Patches on Fatigue Lifetimes. Durability of Metal Aircraft Structures, Ed: Atluri, S. N., Harris, C.E., Hoggard, A., Miller, N/ and Sampath, S. G., Atlanta Technology Publications, pp. 132-145.

[11] Ramesh C., Murthy, M. V. V., Ramamurthy, T. S. and Rao, A. K. (1985). Analytical Estimation of Stress Intensity Factors in Patched Cracked Plates. Eng. Frac. Mech., 21, pp. 479-494. DOI: 10.1016/S0013-7944(85)80041-2.

[12] Liu, T. and Fan, W. (1994). Analysis for an Adhesively Bonded Finite Strip Repair to a Cracked Plate. Eng. Frac. Mech., 47, pp. 629-637. DOI: 10.1016/0013-7944(94)90154-6.

[13] Arendt, C. and Sun, C. T. (1994). Bending Effects of Unsymmetric Adhesively Bonded Composite Repairs on Cracked Aluminium Panels. NASA CP 3274, pp. 33-48.

[14] Fekirini, H., Bouiadjra, B. B., Belhouari, M., Boutabout, B., Serier, B. (2008). Numerical analysis of the performances of bonded composite repair with two adhesive bands in aircraft structures, Composite structures, pp. 8284-8289. DOI: 10.1016/j.compstruct.2006.12.004.

[15] Belhouari, B. B. and Serier, B., (2004). Comparison of double and single bonded repairs to symmetric composite structures: A numerical analysis, composite Structures, 65, pp. 47-53. DOI: 10.1016/j.compstruct.2003.10.005.

[16] Bachir B. B., Belhouari, M. and Serier, B. (2002). Computation of the stress intensity factors for repaired cracks with bonded composite patch in mode I and mixed mode. Composite Structures, 56, pp. 401-406. DOI: $10.1016 /$ S0263-8223(02)00023-5.

[17] Ouinas, D., Bouiadjra, B.B., Serier, B. and Said Bekkouche, M. (2007). The effects of disbands on the stress intensity factor of aluminium panels repaired using composite materials. Compos Struct. 78, pp. 278-84. DOI: $10.1016 /$ j.commatsci.2006.09.006.

[18] Ouinas, D., Hebbar, A. and Vina Olay J. (2006). Fracture Mechanics Modelling of Cracked Aluminium Panel Repaired with Bonded Composite Circular Patch. Journal of Applied Science 9, pp. 2088-2095. DOI: $10.3923 /$ jas.2006.2088.2095

[19] Ouinas D., Ramdane, Z. and Sahnoun M. (2011). Effet de la forme géométrique du patch sur la réduction du FIC en mode I. Journées d’Etudes Nationales de Mécanique, JENM’2011 Ouargla, Algérie.

[20] Mhamdia, R., Bouiadjra, B.B., Serier, B. and Belhouari, M. (2012). The Patch Shape Effects on the Performances of Bonded Composite Repair in Aircraft Structures. Proceedings of the International Conference on Industrial Engineering and Operations Management Istanbul, Turkey. 